Cite this: Food Funct., 2013, 4, 856

Received 13th November 2012

Accepted 27th April 2013

DOI: $10.1039 / c 3 f 030323 c$

www.rsc.org/foodfunction

\section{Review of existing experimental approaches for the clinical evaluation of the benefits of plant food supplements on cardiovascular function}

\author{
Paolo Meoni, ${ }^{* a}$ Patrizia Restani ${ }^{\mathrm{b}}$ and Dalu T. Mancama ${ }^{\mathrm{bc}}$ \\ We conducted a survey of the National Centre for Biotechnology Information (NCBI) PubMed database to \\ identify methods most commonly used for the evaluation of the effect of plant food supplements on the \\ cardiovascular system and their relevance to the regulatory status of these products. Particularly, our search \\ strategy was aimed at the selection of studies concerning the clinical evaluation of the beneficial effects of \\ the most commonly studied plant food supplements acting on the cardiovascular system. Following the \\ screening of 3839 papers for inclusion criteria, 48 published reports were retained for this review. Most \\ studies included in this review used a double blind controlled design, and evaluated the effect of plant \\ food supplements on individuals affected by a disease of the cardiovascular system. The majority of the \\ studies were found to be of low methodological quality on the Jadad scale, mainly because of \\ inadequate reporting of adverse events and of patient withdrawals. In comparison, measures used for \\ the evaluation of benefits included mostly cardiovascular risk factors as recommended in international \\ guidelines and in accordance with principles laid down for the evaluation of health claims in food. The \\ risk factors most frequently evaluated belonged to the category of "lipid function and levels", "heart \\ function" and "blood pressure". For the absolute majority of the studies, the study period did not \\ exceed one month. This review highlights critical factors to be considered in the design of studies \\ evaluating the health effects of plant food supplements on the cardiovascular system. Between others, \\ the inclusion of healthy individuals, better reporting and description of the characteristics of the \\ product used could improve the quality and relevance of these studies.
}

\section{Introduction}

The cardiovascular system is composed of the heart and the network of arteries, veins, and capillaries that transport blood throughout the body, thus delivering oxygen and nutrients necessary to the proper functioning of the organism. Worldwide, cardiovascular disease is estimated to be the leading cause of death and loss of disability-adjusted life years. Cardiovascular diseases are responsible for the largest proportion of deaths due to non-communicable diseases, only followed by cancers and chronic respiratory diseases. ${ }^{1}$

Multivariable assessment has been advocated to estimate absolute cardiovascular disease risk and to guide treatment of risk factors effectively reducing the incidence of these diseases. ${ }^{2,3}$ Several studies have looked at the correlation of

${ }^{a}$ AtuniS Development Services, Bloc B, Avenue H. Bourguiba, 2070 La Marsa, Tunisia. E-mail: meonip@atunis-development.com; Tel: +216 25577167

${ }^{b}$ Dipartimento di Scienze Farmacologiche, Universita di Milano, Via Balzaretti 9, 20133 Milan, Italy. E-mail: patrizia.restani@unimi.it; Fax: +39 0250318284; Tel: +3902 50318371

${ }^{c}$ CSIR Biosciences, PO Box 395, Pretoria 0001, South Africa. E-mail: dmancama@csir. co.za; Fax: +27 12841 4282; Tel: +27 128414282 different factors with the risk of cardiovascular disease in diverse populations, and abnormal lipids, smoking, hypertension, diabetes, abdominal obesity, psychosocial factors, inadequate consumption of fruits and vegetables, high levels of alcohol intake, and lack of regular physical activity account for most of the risk of myocardial infarction worldwide in both sexes and at all ages in all regions. ${ }^{4}$

Based on several lines of evidence, most guidelines ${ }^{2,3}$ advocate a reduction of these risk factors as an effective way of reducing the incidence of cardiovascular disease.

Prevailing dietary recommendations focus on reducing and eliminating unhealthy food components, such as saturated and trans fats, sodium, and added sugar. This is an important way to improve overall diet quality, but there is also increasing interest in finding potentially beneficial ingredients for disease prevention. In particular, emerging evidence indicates that certain foods or their components might mitigate disease risk factors and promote general health and well-being. ${ }^{5}$

Partly because of this close and widely disseminated association between the diet and risk of cardiovascular disease, and partly because of the beliefs concerning the safety and efficacy of plants in maintaining health, many people have turned to 
Plant Food Supplements (PFS) for conditions associated with the cardiovascular system.

Of the 10 top selling herbal dietary supplements in the food, drug and mass market channel in the United States for 2011, ${ }^{6}$ five are often consumed for their purported activity on the cardiovascular system. $^{7}$

Regardless of the widespread use of herbal or plant food supplements, efficacy and safety studies of their activity in human subjects are limited and often methodologically poor ${ }^{8}$ and the selection of the methodology best suited to assess their activity is of the utmost importance both in scientific and regulatory terms.

The objective of this review was to conduct a survey of studies conducted on the most commonly used PFS associated with the health of the cardiovascular system in order to assess the quality of methods and their relevance to the specific regulatory status of PFS.

Food supplements are defined by the Directive 2002/46/EC ${ }^{9}$ of the European Parliament and of the Council as "the foodstuffs for which the purpose is to supplement the normal diet and that are concentrated sources of nutrients or other substances with a nutritional or physiological effect, alone or in combination, marketed in dose form, namely forms such as capsules, pastilles, tablets, pills and other similar forms, sachets of powder, ampoules of liquids, drop dispensing bottles, and other similar forms of liquids and powders designed to be taken in measured small unit quantities". PFS are also defined in this directive as a type of food supplement in which botanical preparations are the main ingredients. ${ }^{9}$

As it can be seen from these definitions and similar definitions applicable to non-European markets, ${ }^{\mathbf{1 0}}$ from a regulatory perspective PFS are assimilated to foodstuff, and the benefit claims allowed in the commercialisation of these products should exclude medical claims such as the prevention, diagnosis and treatment of a recognised pathological state.

This situation clearly requires the careful definition of the population assessed in clinical trials of PFS as well as the biochemical, pharmacological and clinical endpoints and methods to be used in the clinical evaluation of the benefits related to the use of PFS. The evaluation of these aspects within clinical studies of the most commonly researched plants with activity on the cardiovascular system will be the primary objective of this review.

\section{Research design and methods}

\section{Search strategy}

A non-systematic review was conducted of the published studies assessing benefits to the cardiovascular system related to the use of PFS by searching the NCBI PubMed database for studies published between January 1990 and July 2011.

The search used a combination of terms related to the name of plants contained in the EuroFIR EBasis database (Bioactive Substances in Food Information System) and the cardiovascular function. Use of the EBasis database was motivated by its inclusion of data from the peer-reviewed literature representing over 300 major European plant foods. General terms related to the cardiovascular system were combined with keywords related to pathologies included in the 10th edition of the International Classification of Disease ${ }^{\mathbf{1 1}}$ and comprised: heart OR cardiovascular OR hypertension OR hypertensive OR hypotension OR ischemic OR heart disease OR cerebrovascular OR conduction OR arrhythmias OR infarction OR cerebrovascular OR atherosclerosis OR thrombosis OR phlebitis OR haemorrhoids OR varicose.

\section{Inclusion criteria}

To be included in this review, studies had to (i) primarily concern the clinical evaluation of PFS, (ii) include the evaluation of beneficial effects (benefits) of PFS on the cardiovascular system, (iii) be published in the English language, (iv) be representative of the most commonly studied plant ingredients within PFS.

To assess the eligibility of the studies to these inclusion criteria, the following definitions were used:

Benefit - this definition was developed by consortium partners within PlantLIBRA (EC project number 245199): "the attainment of specific physiological objectives, such as reduction of risk factors for chronic diseases and the maintenance of the human homeostasis, which is the body's capability to physiologically regulate well-being and ensure stability and balance in response to changes in the external environment".

Plant food supplements - the definition of PFS was aligned with the EC Directive 2002/46 of the European Parliament and of the Council of 10 June 2002 (ref. 9) on the approximation of the laws of the Member States relating to food supplements: "the foodstuffs (in which botanical preparations are the main ingredients) for which the purpose is to supplement the normal diet and that are concentrated sources of nutrients or other substances with a nutritional or physiological effect, alone or in combination, marketed in dose form, namely forms such as capsules, pastilles, tablets, pills and other similar forms, sachets of powder, ampoules of liquids, drop dispensing bottles, and other similar forms of liquids and powders designed to be taken in measured small unit quantities".

Clinical evaluations: clinical trials based on all study designs including case-control studies, nested case-control studies, crosssectional studies, parallel- or cross-over trials; trials comprising subjects of all conditions, age, gender, and racial groups.

\section{Exclusion criteria}

Studies not in the English language.

\section{Data extraction and quality assessment}

Studies meeting the criteria for selection were extracted into a spread-sheet that captured the following data: trial type (blinding, randomisation, design, duration), population size, methodological quality according to the work of Jadad, ${ }^{\mathbf{1 2}}$ inclusion and exclusion criteria (age, diagnosis, exclusion criteria), treatment (product name, manufacturer, drug substance, country of origin, dosage form, strength), exposure (dosage), outcome measures (outcome, level of significance, technology used), adverse events. 


\section{Results}

\section{Literature search and study characteristics}

The literature search methodology and results are summarised in Table 1. The initial interrogation of the NCBI database with cardiovascular function terms crossed with plant names and synonyms from the EuroFIR database resulted in the identification of 3839 studies of potential relevance. The titles and abstracts of these studies were then screened to identify reports dealing with clinical studies and resulted in a reduced list of 238 reports.

To reduce the number of studies and concentrate the review on PFS containing plant ingredients from most extensively researched plants included in food supplements, we used two different filters: firstly plants mainly used as foods and in a food form (rice, maize, orange, peanut, grapefruit, rye, beetroot, walnut, potato) were excluded resulting in a consolidated list of 159 entries.

Secondly, based on the number of studies identified per plant species, only plants associated with at least three reports of clinical studies were considered as the most extensively researched sources of plant food supplements (Table 2) resulting in the identification of 106 clinical reports considered to be the main focus of this review.

The plants thus identified were: Lycopersicum esculentum or Solanum lycopersicum (tomato), Ruscus aculeatus (Butcher's broom), Centella asiatica (centella), Camellia sinensis (tea),

Table 1 Summary of the literature search methodology and results

Number of papers

Potential studies identified in database search 3839 Studies involving human trials 238 Studies on most extensively researched plants Number of full papers obtained and reviewed Number of papers meeting inclusion criteria

106

100

48

Table 2 Most extensively researched plants based on the present review of clinical studies

\begin{tabular}{lll}
\hline & & $\begin{array}{l}\text { Prioritisation of studies } \\
\text { based on top } \\
\text { non-food plants }\end{array}$ \\
\hline Lycopersicum esculentum & Tomato & 30 \\
Ruscus aculeatus & Butcher's Broom & 11 \\
Centella asiatica & Centella & 9 \\
Camellia sinensis & Tea & 9 \\
Vaccinium macrocarpon & Cranberry & 8 \\
Allium sativum & Garlic & 8 \\
Hibiscus sabdariffa & Roselle & 7 \\
Cynara cardunculus & Artichoke & 6 \\
Panax ginseng & Ginseng & 6 \\
Glycine max & Soy & 4 \\
Citrus aurantum & Bitter orange & 4 \\
Olea europea & Olive tree & 4
\end{tabular}

Vaccinium macrocarpon (cranberry), Allium sativum (garlic), Hibiscus sabdariffa (roselle), Cynara cardunculus or Cynara scolymus (artichoke), Panax ginseng (ginseng), Glycine max or Soy lecithins (soy), Citrus aurantium (bitter orange), Olea europea (olive). Most of these plants were ambivalent, with a significant use as food, but also with a consolidated use as ingredients in PFS (tomato, tea, cranberry, garlic, artichoke, soy, olive) in forms compatible with this class of products.

The full article of each study was subsequently retrieved for detailed examination prior to selecting the final subset of studies for extraction.

Full article reviews were not possible for 6 articles as these were not available from the source, while a further 52 did not meet all inclusion criteria.

The most common reasons for failure to meet inclusion criteria were related to the definition of plant food supplements, mainly due to the lack of processing (so that the plant material was consumed in the same form as a food, like in many reports of tomato-based products) or dose form (as an example, none of the reports identified for cranberry could be included as they were performed on cranberry juice, also commonly used as a food).

Most of the plant food supplements included in this review were administered orally in capsule form (43 out of the 48 studies) followed by liquid forms.

A total of 48 articles were eventually included in the final data extraction set (Table 3); of these 22 were based on doubleblind controlled trials, 21 were based on open trials; and the remainder 5 studies were single blind trials (see Fig. 1).

The majority of the studies used a randomisation method to assign participants to the different treatment groups, with 19/21 double blind studies, $4 / 5$ single blind and 6/21 open studies using randomisation (Fig. 2).

Most studies (26/48) looked at the effect of PFS on individuals affected by a disease recognized in ICD-10 or otherwise identified by the authors, thus referring to the intervention with the PFS as a treatment for patients included in the study. When studies were ranked according to the population considered, the proportion of double blind $v s$. open studies seemed higher in the healthy population (Fig. 3).

\section{Study population and duration}

As summarised in Table 3, the inclusion criteria for the study population and the clinical outcomes being assessed varied widely across studies; these mainly included healthy individuals (26 out of the 48 studies) but a significant number of studies were performed on pre-pathological to pathological cardiovascular conditions ranging from the presence of risk factors (dislypidemias) to minor pathologies (such as minor to moderate superficial venous disease), to chronic diseases (hypertension).

Interestingly, some studies concentrated on borderline conditions (borderline hypertensive, slightly elevated levels of cholesterol) which for the purpose of this review and the classification used in Table 3 were categorized as dealing with healthy populations. 


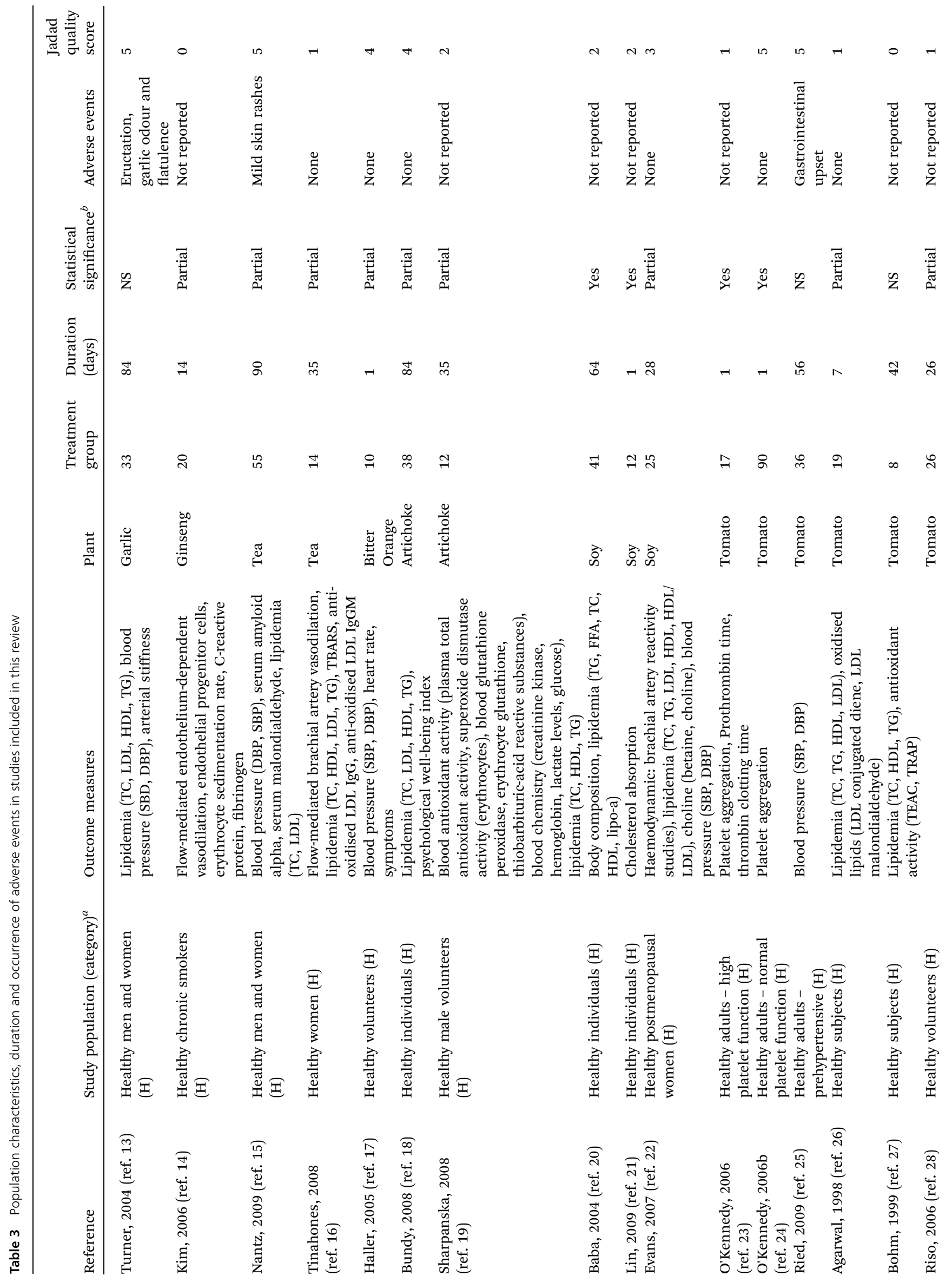




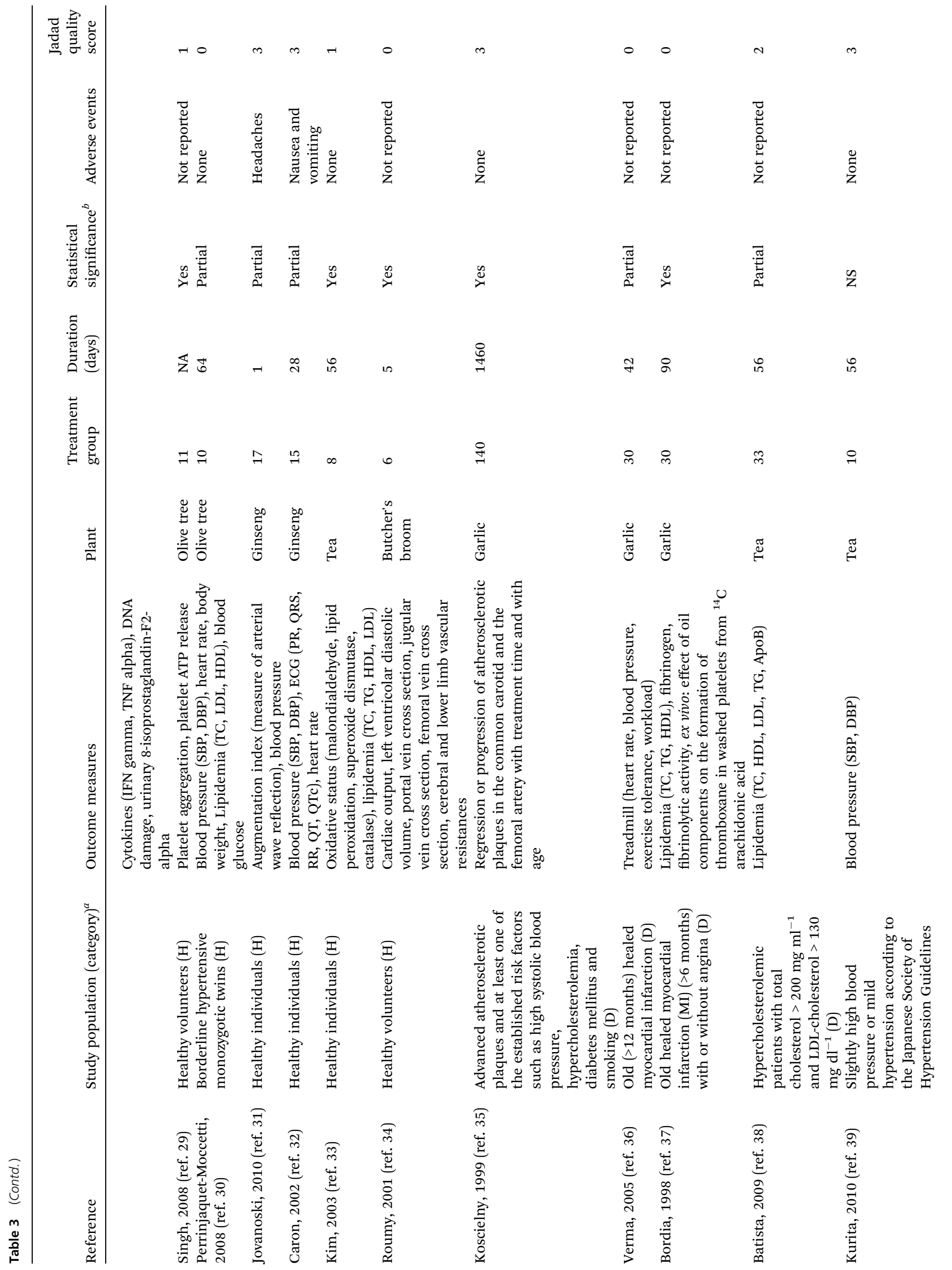




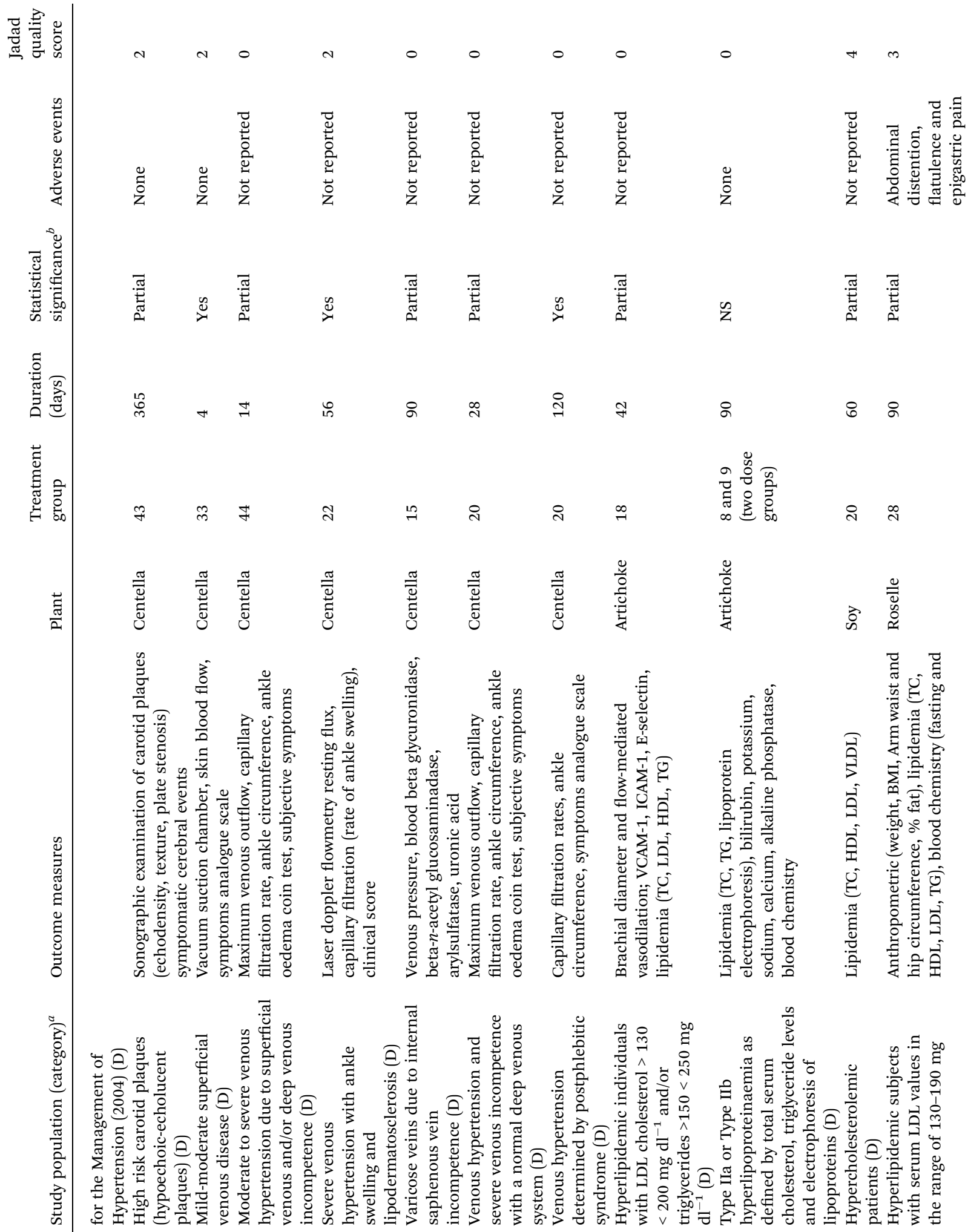

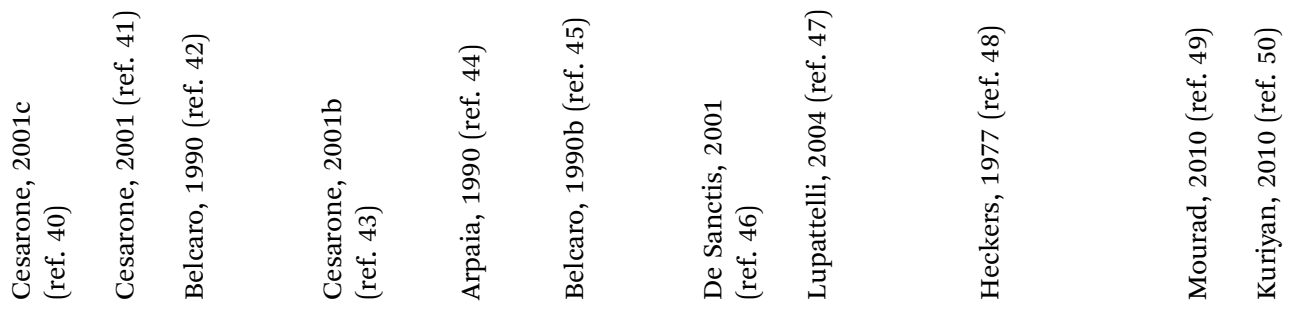




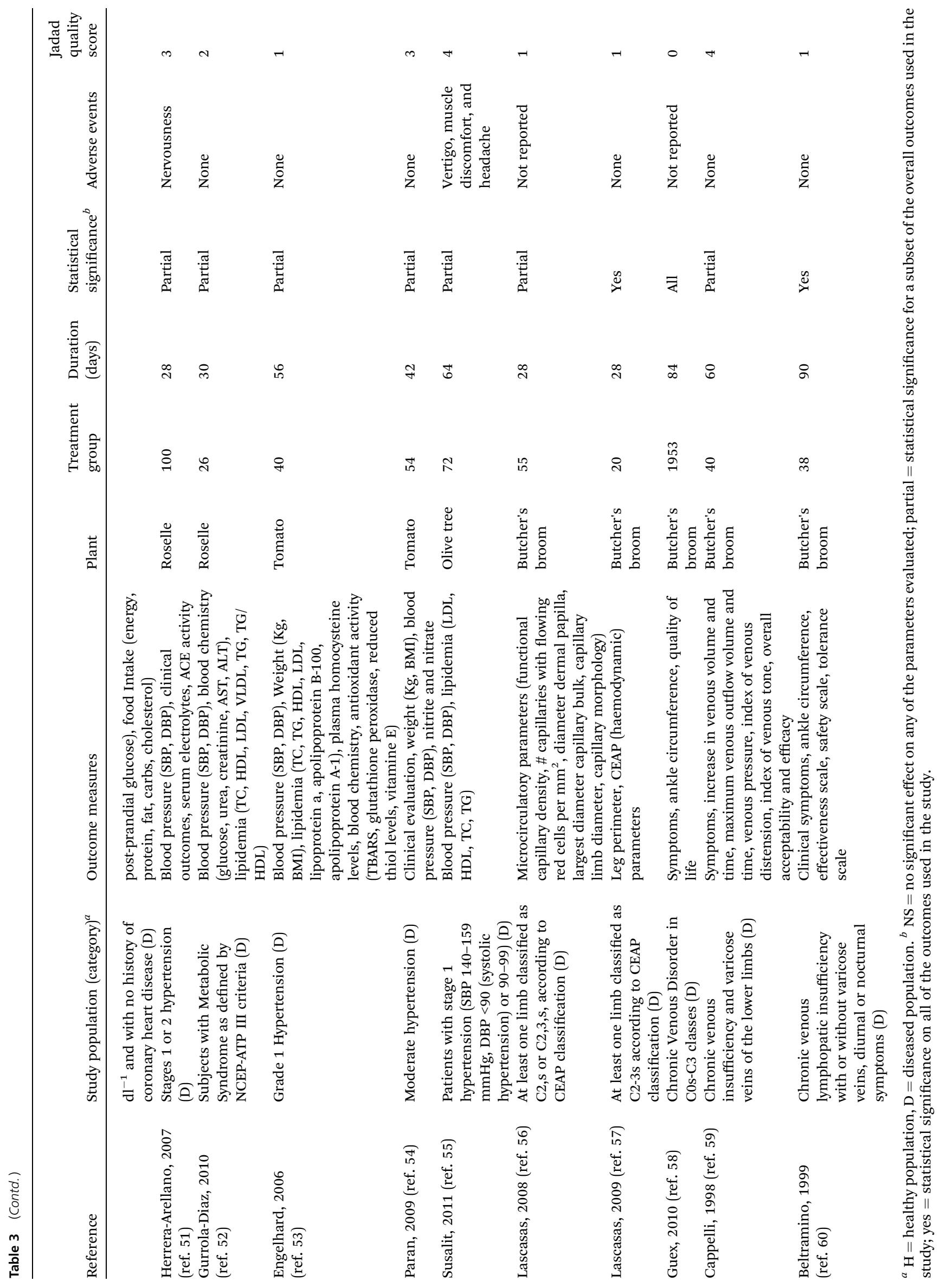




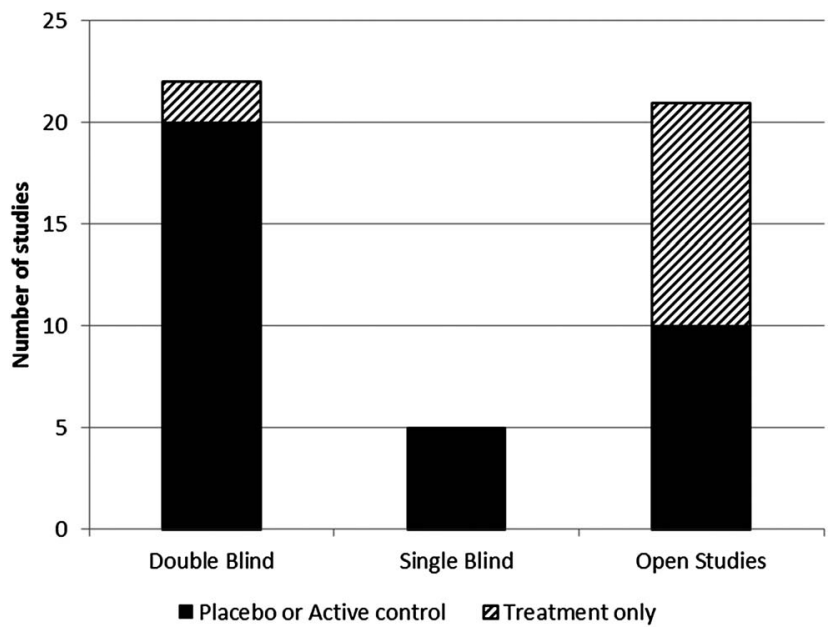

Fig. 1 Repartition of studies according to the study design and the presence of a comparator

The duration of treatment periods included in the studies on average extended to 82 days, with studies on healthy volunteers presenting (on average) a shorter treatment duration (34 days) than studies looking at the effect of PFS in diseased populations (122 days). This difference was mainly driven by three studies looking at the effect of PFS in diseased populations for longer than 4 months, ${ }^{35,40,46}$ and excluding these studies the average duration of studies on diseased populations fell to 53 days.

Average group size across all studies was of 72 individuals, and within this dimension a difference between studies looking at healthy volunteers and diseased population could again be observed (24 versus 112 respectively). Similarly to the analysis of study duration, this difference was mainly driven by three studies $^{\mathbf{3 5 , 5 1 , 5 8}}$ in the diseased population group. Excluding these outliers from the analysis, the average group size between the two categories was more comparable (24 and 31 for the healthy and diseased populations respectively).

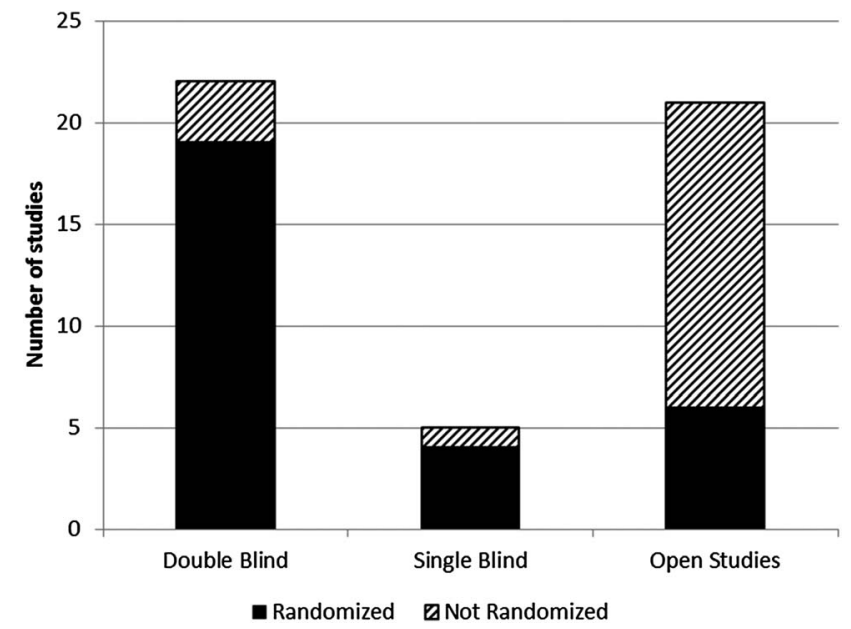

Fig. 2 Repartition of studies according to the randomisation protocol and study design.

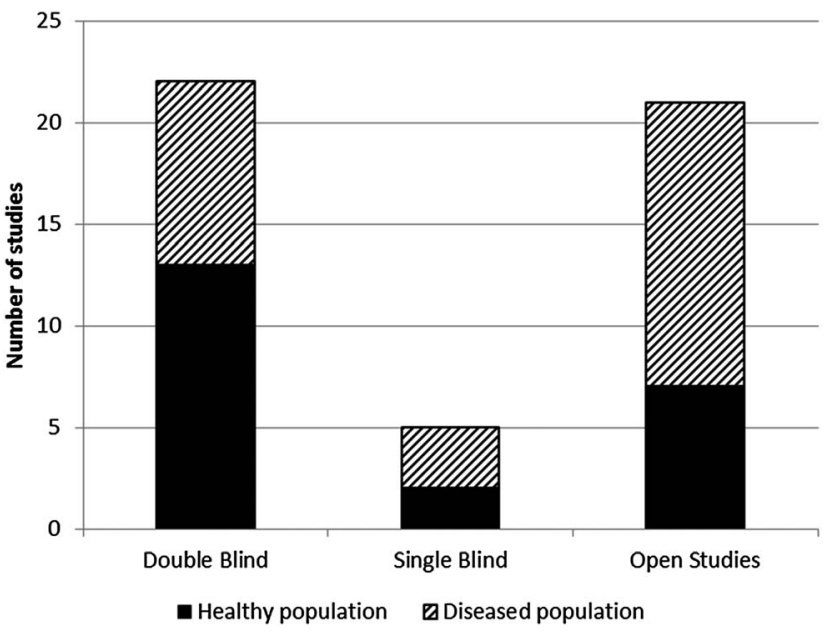

Fig. 3 Repartition of studies according to blinding protocols and the status of the selected population.

\section{Quality of study reporting}

The quality of study reporting was assessed with the Jadad scale ${ }^{12}$ a commonly used instrument to assess the quality of clinical studies. The quality evaluation using this method relies on the rater's evaluation of the report information related to randomization (up to two points), study blinding (up to two points) and description of withdrawals and drop-outs (up to one point). Studies with the highest quality would get a maximum of 5 points, while methodologically poor studies would get 0 points.

For the purpose of this review, a score of $0-2$ would be considered as a low quality study while scores of 3-5 be associated with high quality.

The overall quality of study design, as assessed by the methodological quality score in the data extraction form (as defined in 12) was found to vary widely across studies. The majority were assessed to be of moderate to low quality (average across all studies 1.875) with a slightly higher proportion of

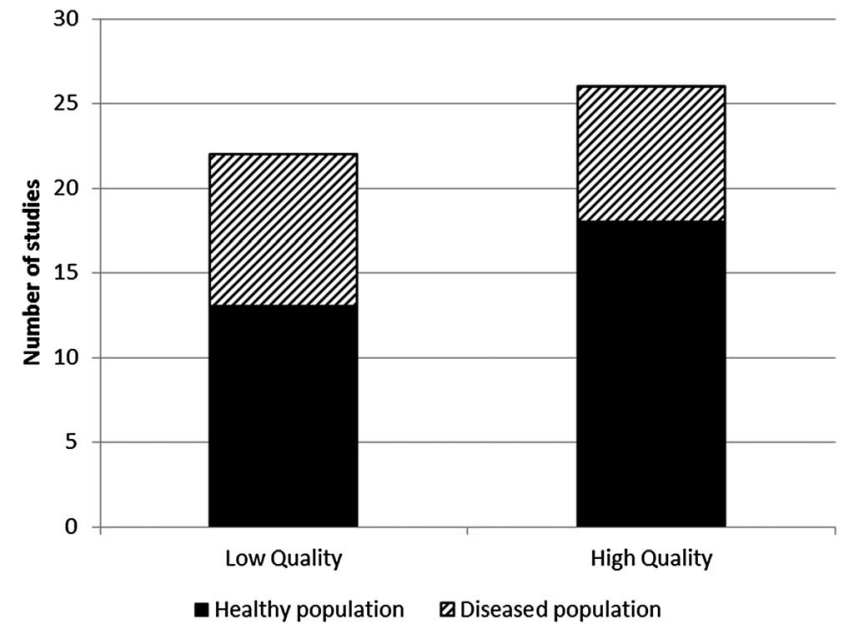

Fig. 4 Repartition of studies according to quality score and the status of the selected population. 
high quality reports (Jadad quality score $>2$ ) within studies of healthy populations (Fig. 4).

Studies looking at the effects of plant food supplements in healthy individuals had a higher proportion of high-quality studies (41\% vs. $31 \%$ in studies on diseased populations) and a higher proportion of double-blind, randomised and controlled studies (59\% vs. $34 \%$ in studies on diseased populations) (Fig. 4 and Table 3).

Overall, the main reasons for low scores on the Jadad scale were poor reporting of adverse events and withdrawals, followed by incomplete description of randomisation methods and blinding.

\section{Study outcomes}

Most of the studies included in this review looked at a wide number of outcomes, often including a combination of biochemical, functional and clinical measurements. Outcome measures and treatment-related adverse events are summarised in Table 3. The majority of the studies (43 out of 48 , see Table 3 ) reported a significant effect of the PFS on at least one of the benefit measures used to assess its biological activity (partial statistical significance as indicated in Table 3), and only a minority did not observe a significant effect on at least one outcome measure. None of the studies mentioned the inclusion of statistical correction factors for multiple comparisons. Interestingly, most of the five studies ${ }^{\mathbf{1 3 , 2 5 , 2 7 , 3 9 , 4 8}}$ not reporting any significant effect belonged to the lower tier in terms of population size, thus suggesting that this could be a critical factor in the observed lack of efficacy.

A significant proportion of the studies (21 out of 48 ) did not report on the occurrence, nature or prevalence of adverse events observed during or after PFS exposure. Of the studies reporting on adverse events, the majority (19 out of 27) did not record any occurrence, and generally only mild adverse events were observed in conjunction with the use of PFS included in these studies (Table 3).

\section{Methods for assessing the cardiovascular benefits of PFS}

A wide range of methods were identified that are used for assessing the benefits of PFS on cardiovascular function, and these could be categorised into six categories: clinical evaluation; venous and arterial structure and function; heart function and blood pressure; coagulation parameters; lipidemia lipid function and risk factors; inflammatory status and oxidative stress. A list of the methods included in each category is reported in Table 4.

The class presenting the highest diversity and number of methods was the "venous and arterial structure and function" (24 methods), followed by "inflammatory status and oxidative stress" (18 methods) and "lipidemia, lipid function and risk factors"(13 methods). However, many methods identified in this survey were often used only in individual studies (for example the ankle coin test in ref. 45 and the vacuum suction chamber for the measure of oedema in ref. 42) (Tables 3 and 4), so that the number of studies in each category cannot be taken as representative of the popularity of the method.
Table 4 Summary of methods used to assess benefits of plant food supplements on the cardiovascular system

\begin{tabular}{|c|c|}
\hline Category of methods & Methods (references) \\
\hline Clinical evaluation & $\begin{array}{l}\text { Body weight }^{30,50,53,54} \\
\text { BMI }^{50,54} \\
\text { Arm, waist and hip circumference } \\
\text { Body composition } \\
\text { Food intake }^{50} \\
\text { Disease symptoms }^{19,30,48,50-53} \\
\text { Effectiveness scale }^{51,59,60} \\
\text { Safety scale } \\
\text { Tolerance scale }^{60} \\
\text { Quality of life scale }^{18,58} \\
\text { Blood chemistry } \\
{ }^{19,30,48,50-53}\end{array}$ \\
\hline $\begin{array}{l}\text { Venous and arterial } \\
\text { structure and function }\end{array}$ & 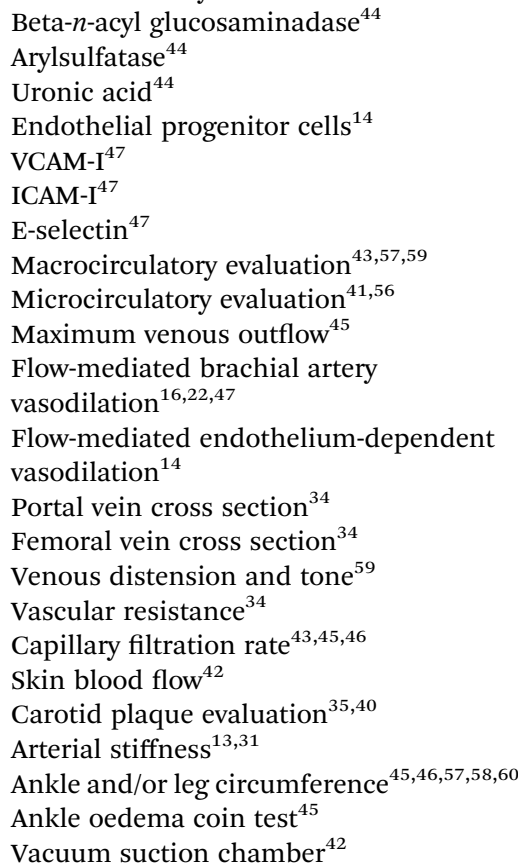 \\
\hline $\begin{array}{l}\text { Heart function and } \\
\text { blood pressure }\end{array}$ & $\begin{array}{l}\text { ECG }^{32} \\
\text { Heart rate } \\
\text { Diastolic and systolic blood } \\
\text { pressure }^{13,15,17,22,25,30-32,39,51-55} \\
\text { Venous pressure } \\
\text { Cardiac output }^{34} \\
\text { Left ventricular diastolic volume } \\
\text { ACE activity } \\
\text { Treadmill (multiple parameters) } \\
\text { T6 }\end{array}$ \\
\hline Coagulation parameters & $\begin{array}{l}\text { Platelet aggregation }{ }^{23,24,29} \\
\text { Platelet ATP release } \\
\text { Prothrombin time }^{23} \\
\text { Thrombin clotting time }^{23} \\
\text { Fibrinogen } \\
\text { Fibrinolytic activity }^{37} \\
\text { Ex vivo thromboxane formation } \\
37\end{array}$ \\
\hline $\begin{array}{l}\text { Lipidemia, lipid function } \\
\text { and risk factors }\end{array}$ & $\begin{array}{l}\mathrm{TC}^{13,15,16,18-22,26,27,30,33,37,38,47-50,52,53,55} \\
\mathrm{HDL}^{13,16,18-20,22,26,27,30,33,37,38,47-50,52,53,55} \\
\mathrm{LDL}^{13,15,16,18,22,26,30,33,38,47-50,52,53,55} \\
\mathrm{VLDL}^{48,49,52} \\
\mathrm{TG}^{13,16,18-20,22,26,27,33,37,38,47,48,52,53,55} \\
\text { Free fatty acids }^{20} \\
\text { Apolipoprotein } \mathrm{A1}^{20,53} \\
\text { Apolipoprotein } \mathrm{B}^{38} \\
\text { Apolipoprotein B100 }\end{array}$ \\
\hline
\end{tabular}


Table 4 (Contd)

\begin{tabular}{|c|c|}
\hline Category of methods & Methods (references) \\
\hline $\begin{array}{l}\text { Inflammatory status and } \\
\text { oxidative stress }\end{array}$ & $\begin{array}{l}\text { Serum amyloid alpha } \\
\text { Plasma homocysteine }^{53} \\
\text { Choline, betaine }^{22} \\
\text { Urinary } 8 \text {-isoprostaglandin-F2-alpha }^{28} \\
\text { IFN gamma } \\
\text { TNF alpha } \\
\text { DNA damage }^{28} \\
\text { Erythrocyte sedimentation rate }^{14} \\
\text { C-reactive protein } \\
\text { LDL-conjugated diene }^{26} \\
\text { LDL malondialdehyde }^{26} \\
\text { Serum malondialdehyde } \\
\text { Anti-oxidised LDL IgG } \\
\text { Anti-oxidised LDL IgM } \\
\text { Total antioxidant activity } \\
\text { Superoxide dismutase } \\
\text { Thiobarbituric acid reactive } \\
\text { substances }^{16,19,53} \\
\text { Glutathione peroxidase } \\
\text { Erythrocyte glutathione }^{19} \\
\text { Plasma thiol levels } \\
\text { Plasma vitamine } \mathrm{E}^{53} \\
\text { Nitrite/nitrate }^{54}\end{array}$ \\
\hline
\end{tabular}

When the frequency of utilisation of the identified methods was taken into account, the methods most often used were those for "lipidemia, lipid function and risk factors" (average utilisation of 6.5), "heart function and blood pressure" (average utilisation 3.0) and "clinical evaluation" (average utilisation 2.9, see details in Table 5). As expected, the class with the highest number of methods (venous and arterial structure and function) was also the one presenting one of the lowest average utilisation per method.

Within the categories, a large variability in utilisation was observed between different methods. The methods most commonly used were lipidemic measures such as TC, HDL, LDL and TG as well as the measure of systolic and diastolic blood pressure which were all used in more than $30 \%$ of the identified studies.

Of particular note was the relatively scarce use of alternative indicators of risk factors (lipoproteins, homocystein, urinary
isoprostaglandin-F2-alpha) and the exclusion of other established biomarkers that may be of particular interest in the context of plant food supplements.

\section{Discussion}

This review was motivated by the perceived poor methodological quality of studies used to assess the efficacy of PFS in cardiovascular disease in light of the absence of clear guidelines concerning their evaluation. Through the review of published studies in this field, we aimed at the determination of the main determinants of these studies and to the assessment of their relevance to the specific regulatory status of PFS.

The analysis of studies included in this review confirmed a wide heterogeneity in the study design and overall quality of evaluations of PFS benefits. While outcomes used for assessing the cardiovascular benefits of PFS seemed generally to be adequate to characterise their activity on the cardiovascular system, two areas of concern could be identified, namely the study design (particularly the population included in the study and the duration of treatment) and the characteristics of the product used.

A number of review papers have already dealt with the toxicological evaluation of plant food supplements currently used in the market ${ }^{61-65}$ and some guidance documents have been made available by different regulatory bodies, ${ }^{65-67}$ the matter related to the evaluation of the benefits associated with the use of plant food supplements remains less explored. EU regulations on nutrition and health claims published in $2006^{68}$ set out the general principle for all health claims to have pre-marketing approval by EFSA, but the regulation did not lay down detailed criteria or requirements for the data supporting a specific health claim (see ref. 69 for a wide overview of the subject).

In the field of standard foods, the PASSCLAIM project ${ }^{70}$ set out criteria for the scientific substantiation of product-specific claims, and the same project recommended an evidence-based assessment of existing studies consisting of the identification, evaluation, and interpretation of individual studies leading to a case-by-case assessment of the validity of the product's health claim. Both the PASSCLAIM project ${ }^{70}$ and the Consensus Document of the Scientific Concepts of Functional Foods in Europe initiative (FUFOSE) indicated that the health promoting

Table 5 Descriptive statistics on method utilisation across the studies included in this review

\begin{tabular}{|c|c|c|c|}
\hline Class of methods & $\begin{array}{l}\text { Number of } \\
\text { methods }\end{array}$ & $\begin{array}{l}\text { Methods utilisation } \\
\text { (number of occurrences in } \\
\text { papers included in this review) }\end{array}$ & $\begin{array}{l}\text { Average } \\
\text { utilisation } \\
\text { per method }^{a}\end{array}$ \\
\hline Clinical evaluation & 11 & 32 & 2.9 \\
\hline $\begin{array}{l}\text { Venous and arterial structure and } \\
\text { function }\end{array}$ & 24 & 37 & 1.5 \\
\hline Heart function and blood pressure & 8 & 24 & 3.0 \\
\hline Coagulation parameters & 7 & 9 & 1.3 \\
\hline $\begin{array}{l}\text { Lipidemia, lipid function and risk } \\
\text { factors }\end{array}$ & 13 & 84 & 6.5 \\
\hline Inflammatory status and Oxidative & 18 & 23 & 1.3 \\
\hline
\end{tabular}
stress

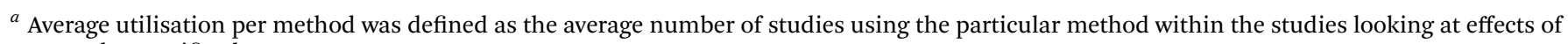
PFS on the specific class. 
effects specific to foods or food components should be mainly exerted through disease risk reduction, thus suggesting that the health-maintaining or promoting effects of PFS could be ideally assessed on disease-progression biomarkers and risk factors (for a review see ref. 69).

Within this context, cardiovascular disease represents an extremely interesting case for the evaluation of methods assessing PFS' benefits as the transition between health and disease and the key markers of this progression have been thoroughly characterised and placed within a continuum. The cardiovascular disease continuum was first described as a chain of events, initiated by a myriad of related and unrelated risk factors and progressing through numerous physiological pathways and processes to the development of end-stage heart disease. ${ }^{71}$ While this concept was initially formulated for coronary artery disease, it has now been expanded to different areas of cardiovascular disease sharing similar pathophysiological processes. ${ }^{72,73}$ Within all these diseases, a number of biomarkers and risk factors capable of determining the relative position of specific individuals along this continuum from health to disease have been described. ${ }^{3,4,74}$

Methods more often used in studies included in this review seemed to be appropriate for the evaluation of their impact on cardiovascular disease. The three categories of methods with the highest average utilisation per method were represented by the "lipidemia, lipid function and risk factors", "heart function and blood pressure" and "general clinical evaluation" (including symptoms but also general body parameters and quality of life scales).

Most guidelines ${ }^{2,3}$ recommend cardiovascular risk evaluation in healthy individuals including factors included in these high average utilisation classes and including the measure of body parameters (weight, BMI), cholesterol levels (TC, HDL, LDL) and blood pressure.

Lipidemia (including total cholesterol, HDL and LDL cholesterol) and systolic and diastolic blood pressure were the most frequent methods assessing the effect of plant food supplements, and are the key factors in the evaluation of the risk of cardiovascular disease. As these parameters are commonly evaluated in clinical practice, clinical and laboratory methods that are both affordable and reliable are widely available and should be routinely used in the evaluation of PFS activity on the cardiovascular system.

In comparison, biomarkers associated with an intermediate level of evidence in guidelines from the American Societies (C-reactive protein, hemoglobin A1C, urinary albumin excretion, lipoprotein-associated phospholipase A2), ${ }^{3}$ or other novel biomarkers of late (creatine kinase and creatine kinase-MB, myoglobin, lipoprotein A, brain natriuretic peptide, troponins I and $\mathrm{T}$, osteopontin) and early stage (asymmetric dimethylarginine, myeloperoxidase, F2 isoprostanes between others) diagnostic potential $^{74}$ were hardly included in the studies reviewed here.

In conclusion, while biomarkers commonly recommended for cardiovascular risk evaluation were included in the majority of the studies, inclusion of wider panels of biomarkers and risk factors could be particularly desirable and useful in profiling and characterising the health effects of plants commonly used in PFS used to promote cardiovascular function.
Access to a larger panel of biomarkers could both provide more resolution for fingerprinting and differentiating the effects of different PFS, and more information on the timecourse of the PFS effect at different stages of the continuum.

Critical features affecting the overall quality of studies supporting product-specific claims were discussed within the PASSCLAIM project. The most important features were identified as the appropriateness and validity of the study methodology used, the completeness and description of analytical measures and the adequacy of the study population, between others. $^{70}$ These important features also appear critical from the analysis of the studies included in this review. In particular, the study population and study methodology (particularly the design and duration of the studies) did not always seem adequate for the evaluation of PFS benefits.

Over half of the studies identified in this review dealt with patient populations diagnosed with pathological conditions ranging from mild arterial or venous hypertension, to varicose veins, to more severe and possibly life threatening conditions such as severe hypertension or advanced atherosclerotic plaques in the presence of other risk factors. While this situation could be partly explained by the inclusion of ambivalent plants (i.e. plants used in plant food supplements and medicinal products in different countries), it certainly highlights some confusion in the selection of the population to be assessed for the health maintaining or promoting activity of plant food supplements, and calls for the inclusion of individuals at an earlier stage in the cardiovascular continuum. The study of diseased populations also added specific constraints that diminished the quality of studies: double blind protocols were more difficult to implement in this population, and the overall quality score was lower. The low quality scores of the studies on the Jadad scale were associated with important shortcomings in the reporting of adverse events, drop-outs and withdrawals, blinding procedures. While this difference can be partly explained on ethical grounds (patient's lack of improvement can be better detected and more promptly corrected in single blind or open studies), it certainly further supports the use of healthy volunteers in the assessment of the health promoting effects of plant food supplements.

The duration of the studies also differed between healthy and diseased populations, and the comprehension of this difference should be key to the formulation of recommendations for further studies. The longer duration of the studies in diseased populations corresponds to the inclusion of diseasespecific outcomes whose regression to normal values is slower than any effect on risk factors. Parameters of venous and arterial function in circulatory disease, blood pressure and lipidemia in hypertensive and hyperlipidemic patients or plaques regression in atherosclerotic patients for example required long intervention times than studies looking at risk factors in healthy volunteers. As an example, the two longest studies included in this review ${ }^{35,40}$ both looked at the most severe condition included in this study set: plaques regression and characteristics in patients with advanced and/or high risk atherosclerotic plaques.

Therefore, considering the regulatory status of PFS and their suggested activity in the reduction of risk factors, ${ }^{69,70}$ durations 
of two to three weeks should generally be considered sufficient to highlight a physiological effect and be deemed sufficient to study PFS benefits on biomarkers related to the cardiovascular system.

A final consideration concerns the description of the material used in the studies. As mentioned previously, the formulation as well as the process and the chemical characterisation of the raw and final material is key to determine the identity and quality of the PFS, and the belonging of a certain product to the category of Food Supplement, Food or Medicine.

Many studies were performed on plant material that was poorly characterised or whose formulation was not sufficiently described and generally did not correspond to the commercial formulations available in shops. Very few studies included in this review for example provided a commercial name or the exact composition of the product tested.

More stringent criteria should be applied to the characterisation of the PFS ingredients (standardisation, chemical profiling, quantitative content of biomarker molecules) as well as on the pharmaceutical form used for the study to improve the relevance of study results to the actual use of the product on the market.

In conclusion, while the results of this review cannot be fully representative of all the studies conducted on cardiovascular effects of PFS, they highlight some areas of major concern in the design of studies for the assessment of PFS benefits in cardiovascular disease: firstly, studies should be conducted on healthy populations, using a wider panel of measures and for durations sufficient to unequivocally assess the effect on risk factors and associated clinical outcomes; secondly, study reports should report more precisely protocol details (randomisation, blinding, statistical analysis) as well as study-related events such as adverse events and withdrawals. Finally, interventions should be better characterised from the product perspective by adequately describing the composition and formulation of the PFS.

\section{Abbreviations}

$\begin{array}{ll}\text { ACE } & \text { Angiotensin Converting Enzyme } \\ \text { BMI } & \text { Body-Mass Index } \\ \text { DBP } & \text { Dyastolic Blood Pressure } \\ \text { HDL } & \text { High-Density Lipoproteins } \\ \text { IFN } & \text { Interferon } \\ \text { LDL } & \text { Low-Density Lipoproteins } \\ \text { SBP } & \text { Systolic Blood Pressure } \\ \text { TBARS } & \text { Thiobarbituric Acid Reactive Substances } \\ \text { TC } & \text { Total Cholesterol } \\ \text { TEAC } & \text { Trolox Equivalent Antioxidant Capacity } \\ \text { TG } & \text { Triglycerides } \\ \text { TNF } & \text { Tumor Necrosis Factor } \\ \text { TRAP } & \text { Total Reactive Antioxidant Potential } \\ \text { VLDL } & \text { Very Low-Density Lipoproteins }\end{array}$

\section{Acknowledgements}

The authors would like to thank Prof. G. Williamson for his valuable insight on previous versions of this manuscript.

\section{Notes and references}

1 World Health Organisation, World Health Statistics 2012, http:/www.who.int/gho/publications/world_health_statistics/ 2012/en/, accessed October 2012.

2 European Association for Cardiovascular Prevention and Rehabilitation, Z. Reiner, A. L. Catapano, G. De Backer, I. Graham, M. R. Taskinen, O. Wiklund, S. Agewall, E. Alegria, M. J. Chapman, P. Durrington, S. Erdine, J. Halcox, R. Hobbs, J. Kjekshus, P. P. Filardi, G. Riccardi, R. F. Storey and D. Wood, Esc Committee for practice guidelines (CPG) 2008-2010 and 2010-2012 Committees. (UK), John Kjekshus (Norway), Pasquale Perrone Filardi (Italy), Gabriele Riccardi. ESC/EAS guidelines for the management of dyslipidaemias: the Task Force for the management of dyslipidaemias of the European Society of Cardiology (ESC) and the European atherosclerosis Society (EAS), Eur. Heart J., 2011, 32(14), 1769-1818.

3 P. Greenland, J. S. Alpert, G. A. Beller, E. J. Benjamin, M. J. Budoff, Z. A. Fayad, E. Foster, M. A. Hlatky, J. M. Hodgson, F. G. Kushner, M. S. Lauer, L. J. Shaw, S. C. Smith Jr, A. J. Taylor, W. S. Weintraub, N. K. Wenger, A. K. Jacobs, S. C. Smith Jr, J. L. Anderson, N. Albert, C. E. Buller, M. A. Creager, S. M. Ettinger, R. A. Guyton, J. L. Halperin, J. S. Hochman, F. G. Kushner, R. Nishimura, E. M. Ohman, R. L. Page, W. G. Stevenson, L. G. Tarkington and C. W. Yancy, American College of Cardiology Foundation; American Heart Association, 2010 ACCF/AHA guideline for assessment of cardiovascular risk in asymptomatic adults: a report of the American College of Cardiology Foundation/American Heart Association Task Force on Practice Guidelines, J Am Coll Cardiol, 2010, 56(25), e50-103.

4 S. Yusuf, S. Hawken, S. Ounpuu, T. Dans, A. Avezum, F. Lanas, M. McQueen, A. Budaj, P. Pais, J. Varigos and L. Lisheng, INTERHEART Study Investigators, Effect of potentially modifiable risk factors associated with myocardial infarction in 52 countries (the INTERHEART study): case-control study, Lancet, 2004, 364(9438), 937-952.

$5 \mathrm{~F}$. B. Hu, Do functional foods have a role in the prevention of cardiovascular disease?, Circulation, 2011, 124(5), 538-540.

6 M. Blumenthal, A. Lindstrom, C. Ooyen and M. E. Lynch, Herb Supplement Sales Increase $4.5 \%$ in 2011, Herbalgram, 2012, 95, 60-64.

7 Memorial Sloan-Kettering Cancer Center, About Herbs, Botanicals and Other Products, http://www.mskcc.org/cancercare/integrative-medicine/about-herbs-botanicals-other-pro ducts, accessed November 2012.

8 B. R. Cassileth, M. Heitzer and K. Wesa, The Public Health Impact of Herbs and Nutritional Supplements, Pharm. Biol., 2009, 47(8), 761-767.

9 DIRECTIVE 2002/46/EC OF the European Parliament and of the Council of 10 June 2002 on the approximation of the laws of the Member States relating to food supplements, Official Journal of the European Communities, http://eur-lex.europa. eu/LexUriServ/LexUriServ.do?uri=OJ:L:2002:183:0051:0057: EN:PDF 
10 United States Food and Drug Administration Dietary Supplement Health and Education Act of 1994, http://www. fda.gov/RegulatoryInformation/Legislation/FederalFoodDrug andCosmeticActFDCAct/SignificantAmendmentstotheFDCA ct/ucm148003.htm.

11 International Statistical Classification of Diseases and Related Health Problems 10th Revision, http://apps.who.int/ classifications/icd10/browse/2010/en, accessed July 2011.

12 A. R. Jadad, R. A. Moore, D. Carroll, C. Jenkinson, D. J. Reynolds, D. J. Gavaghan and H. J. McQuay, Assessing the quality of reports of randomized clinical trials: is blinding necessary?, Controlled Clin. Trials, 1996, 17(1), 1-12.

13 B. Turner, C. Mølgaard and P. Marckmann, Effect of garlic (Allium sativum) powder tablets on serum lipids, blood pressure and arterial stiffness in normo-lipidaemic volunteers: a randomised, double-blind, placebo-controlled trial, Br. J. Nutr., 2004, 92(4), 701-706.

14 W. Kim, M. H. Jeong, S. H. Cho, J. H. Yun, H. J. Chae, Y. K. Ahn, M. C. Lee, X. Cheng, T. Kondo, T. Murohara and J. C. Kang, Effect of green tea consumption on endothelial function and circulating endothelial progenitor cells in chronic smokers, Circ. J., 2006 Aug, 70(8), 1052-1057.

15 M. P. Nantz, C. A. Rowe, J. F. Bukowski and S. S. Percival, Standardized capsule of Camellia sinensis lowers cardiovascular risk factors in a randomized, double-blind, placebo-controlled study, Nutrition, 2009, 25(2), 147-154.

16 F. J. Tinahones, M. A. Rubio, L. Garrido-Sánchez, C. Ruiz, E. Gordillo, L. Cabrerizo and F. Cardona, Green tea reduces LDL oxidability and improves vascular function, J. Am. Coll. Nutr., 2008, 27(2), 209-213.

17 C. A. Haller, N. L. Benowitz and P. Jacob III, Hemodynamic effects of ephedra-free weight-loss supplements in humans, Am. J. Med., 2005, 118(9), 998-1003.

18 R. Bundy, A. F. Walker, R. W. Middleton, C. Wallis and H. C. Simpson, Artichoke leaf extract (Cynara scolymus) reduces plasma cholesterol in otherwise healthy hypercholesterolemic adults: a randomized, double blind placebo controlled trial, Phytomedicine, 2008, 15(9), 668675.

19 A. Skarpanska-Stejnborn, L. Pilaczynska-Szczesniak, P. Basta, E. Deskur-Smielcka and M. Horoszkiewicz-Hassan, The influence of supplementation with artichoke (Cynara scolymus L.) extract on selected redox parameters in rowers, Int. J. Sport Nutr. Exercise Metab., 2008, 18(3), 313-327.

20 T. Baba, A. Ueda, M. Kohno, K. Fukui, C. Miyazaki, M. Hirotsuka and M. Ishinaga, Effects of soybean betaconglycinin on body fat ratio and serum lipid levels in healthy volunteers of female university students, J. Nutr. Sci. Vitaminol., 2004, 50(1), 26-31.

21 X. Lin, L. Ma, S. B. Racette, C. L. Anderson Spearie and R. E. Ostlund Jr, Phytosterol glycosides reduce cholesterol absorption in humans, Am. J. Physiol.: Gastrointest. Liver Physiol., 2009, 296(4), G931-G935.

22 M. Evans, V. Y. Njike, M. Hoxley, M. Pearson and D. L. Katz, Effect of soy isoflavone protein and soy lecithin on endothelial function in healthy postmenopausal women, Menopause, 2007, 14(1), 141-149.
23 N. O'Kennedy, L. Crosbie, M. van Lieshout, J. I. Broom, D. J. Webb and A. K. Duttaroy, Effects of antiplatelet components of tomato extract on platelet function in vitro and ex vivo: a time-course cannulation study in healthy humans, Am. J. Clin. Nutr., 2006, 84(3), 570-579.

24 N. O'Kennedy, L. Crosbie, S. Whelan, V. Luther, G. Horgan, J. I. Broom, D. J. Webb and A. K. Duttaroy, Effects of tomato extract on platelet function: a double-blinded crossover study in healthy humans, Am. J. Clin. Nutr., 2006, 84(3), 561-569.

25 K. Ried, O. R. Frank and N. P. Stocks, Dark chocolate or tomato extract for prehypertension: a randomised controlled trial, BMC Complementary Altern. Med., 2009, 9, 22.

26 S. Agarwal and A. V. Rao, Tomato lycopene and low density lipoprotein oxidation: a human dietary intervention study, Lipids, 1998, 33(10), 981-984.

27 V. Böhm and R. Bitsch, Intestinal absorption of lycopene from different matrices and interactions to other carotenoids, the lipid status, and the antioxidant capacity of human plasma, Eur. J. Nutr., 1999 Jun, 38(3), 118-125.

28 P. Riso, F. Visioli, S. Grande, S. Guarnieri, C. Gardana, P. Simonetti and M. Porrini, Effect of a tomato-based drink on markers of inflammation, immunomodulation, and oxidative stress, J. Agric. FoodChem., 2006, 54(7), 2563-2566.

29 I. Singh, M. Mok, A. M. Christensen, A. H. Turner and J. A. Hawley, The effects of polyphenols in olive leaves on platelet function, Nutr., Metab. Cardiovasc. Dis., 2008, 18(2), 127-132.

30 T. Perrinjaquet-Moccetti, A. Busjahn, C. Schmidlin, A. Schmidt, B. Bradl and C. Aydogan, Food supplementation with an olive (Olea europaea L.) leaf extract reduces blood pressure in borderline hypertensive monozygotic twins, Phytother. Res., 2008, 22(9), 1239-1242.

31 E. Jovanovski, A. Jenkins, A. G. Dias, V. Peeva, J. Sievenpiper, J. T. Arnason, D. Rahelic, R. G. Josse and V. Vuksan, Effects of Korean red ginseng (Panax ginseng C. A. Mayer) and its isolated ginsenosides and polysaccharides on arterial stiffness in healthy individuals, Am. J. Hypertens., 2010, 23(5), 469-472.

32 M. F. Caron, A. L. Hotsko, S. Robertson, L. Mandybur, J. Kluger and C. M. White, Electrocardiographic and hemodynamic effects of Panax ginseng, Ann. Pharmacother., 2002, 36(5), 758-763.

33 S. H. Kim and K. S. Park, Effects of Panax ginseng extract on lipid metabolism in humans, Pharmacol. Res., 2003, 48(5), 511-513.

34 J. Roumy, S. Herault, N. Tobal, S. Besnard and P. Arbeille, Effect of a venotonic agent on the main arteries and veins during a 5 day HDT, Acta Astronaut., 2001, 49(3-10), 161-166.

35 J. Koscielny, D. Klüssendorf, R. Latza, R. Schmitt, H. Radtke, G. Siegel and H. Kiesewetter, The antiatherosclerotic effect of Allium sativum, Atherosclerosis, 1999, 144(1), 237-249.

36 S. K. Verma, V. Rajeevan, P. Jain and A. Bordia, Effect of garlic (Allium sativum) oil on exercise tolerance in patients with coronary artery disease, Indian J. Physiol. Pharmacol., 2005, 49(1), 115-118.

37 A. Bordia, S. K. Verma and K. C. Srivastava, Effect of garlic (Allium sativum) on blood lipids, blood sugar, fibrinogen 
and fibrinolytic activity in patients with coronary artery disease, Prostaglandins, Leukotrienes Essent. Fatty Acids, 1998, 58(4), 257-263.

38 A. Batista Gde, C. L. Cunha, M. Scartezini, R. von der Heyde, M. G. Bitencourt and S. F. Melo, Prospective double-blind crossover study of Camellia sinensis (green tea) in dyslipidemias, Arq. Bras. Cardiol., 2009, 93(2), 128-134.

39 I. Kurita, M. Maeda-Yamamoto, H. Tachibana and M. Kamei, Antihypertensive effect of Benifuuki tea containing O-methylated EGCG, J. Agric. Food Chem., 2010, 58(3), 1903-1908.

40 M. R. Cesarone, G. Belcaro, A. N. Nicolaides, G. Geroulakos, M. Bucci, M. Dugall, M. T. De Sanctis, L. Incandela, M. Griffin and M. Sabetai, Increase in echogenicity of echolucent carotid plaques after treatment with total triterpenic fraction of Centella asiatica: a prospective, placebo-controlled, randomized trial, Angiology, 2001, 52(suppl. 2), S19-S25.

41 M. R. Cesarone, L. Incandela, M. T. De Sanctis, G. Belcaro, G. Geroulakos, M. Griffin, A. Lennox, A. D. Di Renzo, M. Cacchio and M. Bucci, Flight microangiopathy in medium- to long-distance flights: prevention of edema and microcirculation alterations with total triterpenic fraction of Centella asiatica, Angiology, 2001, 52(suppl. 2), S33-S37.

42 G. V. Belcaro, R. Grimaldi and G. Guidi, Improvement of capillary permeability in patients with venous hypertension after treatment with TTFCA, Angiology, 1990, 41(7), 533-540.

43 M. R. Cesarone, G. Belcaro, M. T. De Sanctis, L. Incandela, M. Cacchio, P. Bavera, E. Ippolito, M. Bucci, M. Griffin, G. Geroulakos, M. Dugall, S. Buccella, S. Kleyweght and M. Cacchio, Effects of the total triterpenic fraction of Centella asiatica in venous hypertensive microangiopathy: a prospective, placebo-controlled, randomized trial, Angiology, 2001, 52(suppl. 2), S15-S18.

44 M. R. Arpaia, R. Ferrone, M. Amitrano, C. Nappo, G. Leonardo and R. del Guercio, Effects of Centella asiatica extract on mucopolysaccharide metabolism in subjects with varicose veins, Int. J. Clin. Pharmacol. Res., 1990, 10(4), 229-233.

45 G. V. Belcaro, A. Rulo and R. Grimaldi, Capillary filtration and ankle edema in patients with venous hypertension treated with TTFCA, Angiology, 1990, 41(1), 12-18.

46 M. T. De Sanctis, G. Belcaro, L. Incandela, M. R. Cesarone, M. Griffin, E. Ippolito and M. Cacchio, Treatment of edema and increased capillary filtration in venous hypertension with total triterpenic fraction of Centella asiatica: a clinical, prospective, placebo-controlled, randomized, dose-ranging trial, Angiology, 2001, 52(suppl. 2), S55-S59.

47 G. Lupattelli, S. Marchesi, R. Lombardini, A. R. Roscini, F. Trinca, F. Gemelli, G. Vaudo and E. Mannarino, Artichoke juice improves endothelial function in hyperlipemia, Life Sci., 2004, 76(7), 775-782.

48 H. Heckers, K. Dittmar, F. W. Schmahl and K. Huth, Inefficiency of cynarin as therapeutic regimen in familial type II hyperlipoproteinaemia, Atherosclerosis, 1977, 26(2), 249-253.

49 A. M. Mourad, E. de Carvalho Pincinato, P. G. Mazzola, M. Sabha and P. Moriel, Influence of soy lecithin administration on hypercholesterolemia, Cholesterol, 2010, 2010, 824813.

50 R. Kuriyan, D. R. Kumar, R. Rajendran and A. V. Kurpad, An evaluation of the hypolipidemic effect of an extract of Hibiscus Sabdariffa leaves in hyperlipidemic Indians: a double blind, placebo controlled trial, BMC Complementary Altern. Med., 2010, 10, 27.

51 A. Herrera-Arellano, J. Miranda-Sánchez, P. Avila-Castro, S. Herrera-Alvarez, J. E. Jiménez-Ferrer, A. Zamilpa, R. Román-Ramos, H. Ponce-Monter and J. Tortoriello, Clinical effects produced by a standardized herbal medicinal product of Hibiscus sabdariffa on patients with hypertension. A randomized, double-blind, lisinoprilcontrolled clinical trial, Planta Med., 2007, 73(1), 6-12.

52 C. M. Gurrola-Díaz, P. M. García-López, S. Sánchez-Enríquez, R. Troyo-Sanromán, I. Andrade-González and J. F. GómezLeyva, Effects of Hibiscus sabdariffa extract powder and preventive treatment (diet) on the lipid profiles of patients with metabolic syndrome (MeSy), Phytomedicine, 2010, 17(7), 500-505.

53 Y. N. Engelhard, B. Gazer and E. Paran, Natural antioxidants from tomato extract reduce blood pressure in patients with grade-1 hypertension: a double-blind, placebo-controlled pilot study, Am. Heart J., 2006, 151(1), 100.

54 E. Paran, V. Novack, Y. N. Engelhard and I. Hazan-Halevy, The effects of natural antioxidants from tomato extract in treated but uncontrolled hypertensive patients, Cardiovasc. Drugs Ther., 2009, 23(2), 145-151.

55 E. Susalit, N. Agus, I. Effendi, R. R. Tjandrawinata, D. Nofiarny, T. Perrinjaquet-Moccetti and M. Verbruggen, Olive (Olea europaea) leaf extract effective in patients with stage-1 hypertension: comparison with Captopril, Phytomedicine, 2011, 18(4), 251-258.

56 C. L. Lascasas-Porto, A. L. Milhomens, C. E. VirginiMagalhães, F. F. Fernandes, F. L. Sicuro and E. Bouskela, Use of microcirculatory parameters to evaluate clinical treatments of chronic venous disorder (CVD), Microvasc. Res., 2008, 76(1), 66-72.

57 C. L. Lascasas-Porto, A. L. Milhomens, C. E. Pires, S. S. Xavier, F. Sicuro, D. A. Bottino and E. Bouskela, Changes on venous diameter and leg perimeter with different clinical treatments for moderate chronic venous disease: evaluation using Duplex scanning and perimeter measurements, Int. J. Angiol., 2009, 28(3), 222-231.

58 J. J. Guex, L. Avril, E. Enrici, E. Enriquez, C. Lis and C. Taïeb, Quality of life improvement in Latin American patients suffering from chronic venous disorder using a combination of Ruscus aculeatus and hesperidin methyl-chalcone and ascorbic acid (quality study), Int. J. Angiol., 2010, 29(6), 525-532.

59 R. Cappelli, M. Nicora and T. Di Perri, Use of extract of Ruscus aculeatus in venous disease in the lower limbs, Drugs Exp. Clin. Res., 1988, 14(4), 277-283.

60 R. Beltramino, A. Penenory and A. M. Buceta, An open-label, randomised multicentre study comparing the efficacy and safety of CYCLO 3 FORT versus hydroxyethyl rutoside in chronic venous lymphatic insufficiency, Int. J. Angiol., 1999, 18(4), 337-342. 
61 B. Schilter, C. Andersson, R. Anton, A. Constable, J. Kleiner, J. O'Brien, A. G. Renwick, O. Korver, F. Smit and R. Walker, Guidance for the safety assessment of botanicals and botanical preparations for use in food and food supplements, Food Chem. Toxicol., 2003, 41(12), 1625-1649.

62 R. B. van Breemen, H. H. Fong and N. R. Farnsworth, Ensuring the safety of botanical dietary supplements, Am. J. Clin. Nutr., 2008, 87(2), 509S-513S.

63 S. A. Jordan, D. G. Cunningham and R. J. Marles, Assessment of herbal medicinal products: challenges, and opportunities to increase the knowledge base for safety assessment., Toxicol. Appl. Pharmacol., 2010, 243(2), 198-216.

64 A. Abdel-Rahman, N. Anyangwe, L. Carlacci, S. Casper, R. P. Danam, E. Enongene, G. Erives, D. Fabricant, R. Gudi, C. J. Hilmas, F. Hines, P. Howard, D. Levy, Y. Lin, R. J. Moore, E. Pfeiler, T. S. Thurmond, S. Turujman and N. J. Walker, The safety and regulation of natural products used as foods and food ingredients, Toxicol. Sci., 2011, 123(2), 333-348.

65 European Food Safety Authority (EFSA) Scientific Committee, Scientific opinion: guidance on safety assessment of botanicals and botanical preparations intended for use as ingredients in food supplements, EFSA J., 2009, 7(9), 1249.

66 ESCO working group on botanicals and botanical preparations, Advice on the EFSA guidance document for the safety assessment of botanicals and botanical preparations intended for use as food supplements, based on real case studies, EFSA J., 2009, 7(9), 280.

67 United States Food and Drug Administration, Dietary Supplement Health and Education Act of 1994, http://www. fda.gov/RegulatoryInformation/Legislation/FederalFoodDrug andCosmeticActFDCAct/SignificantAmendmentstotheFDCA ct/ucm148003.htm, accessed October 2012.
68 European Parliament and the Council, Regulation (EC) No 1924/2006 of 20 December 2006 on nutrition and health claims made on foods.

69 P. Coppens, L. Delmulle, O. Gulati, D. Richardson, M. Ruthsatz, H. Sievers and S. Sidani, European Botanical Forum, use of botanicals in food supplements, regulatory scope, scientific risk assessment and claim substantiation, Ann. Nutr. Metab., 2006, 50(6), 538-554.

70 D. P. Richardson, T. Affertsholt, N. G. Asp, A. Bruce, R. Grossklaus, J. Howlett, D. Pannemans, R. Ross, H. Verhagen and V. Viechtbauer, PASSCLAIM - Synthesis and review of existing processes, Eur. J. Nutr., 2003, 42(suppl. 1), I96-I111.

71 V. Dzau and E. Braunwald, Resolved and unresolved issues in the prevention and treatment of coronary artery disease: a workshopconsensus statement, Am. Heart J., 1991, 121(4 Pt 1), 1244-1263.

72 V. J. Dzau, E. M. Antman, H. R. Black, D. L. Hayes, J. E. Manson, J. Plutzky, J. J. Popma and W. Stevenson, The cardiovascular disease continuum validated: clinical evidence of improved patient outcomes: part I: pathophysiology and clinical trial evidence (risk factors through stable coronary artery disease), Circulation, 2006, 114(25), 2850-2870.

73 V. J. Dzau, E. M. Antman, H. R. Black, D. L. Hayes, J. E. Manson, J. Plutzky, J. J. Popma and W. Stevenson, The cardiovascular disease continuum validated: clinical evidence of improved patient outcomes: part II: clinical trial evidence (acute coronary syndromes through renal disease) and future directions, Circulation, 2006, 114(25), 2871-2891.

74 E. Vassiliadis, N. Barascuk, A. Didangelos and M. A. Karsdal, Novel cardiac-specific biomarkers and the cardiovascular continuum, Biomarker Insights, 2012, 7, 45-57. 